\section{DIGITAL COMMONS \\ @ UNIVERSITY OF SOUTH FLORIDA}

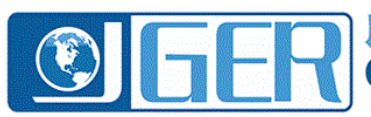

Journal of

Global Education and Research

March 2023

\title{
Defining intercultural competence: How four pre-service teachers developed a more complex understanding of ICC
}

\author{
Elizabeth C. Barrow \\ Georgia Southern University, ebarrow@georgiasouthern.edu
}

Follow this and additional works at: https://digitalcommons.usf.edu/jger

Part of the International and Comparative Education Commons, and the Other Teacher Education and Professional Development Commons

This Refereed Article is brought to you for free and open access by the M3 Center at the University of South Florida Sarasota-Manatee at Digital Commons @ University of South Florida. It has been accepted for inclusion in Journal of Global Education and Research by an authorized editor of Digital Commons @ University of South Florida. For more information, please contact digitalcommons@usf.edu.

\section{Recommended Citation}

Barrow, E. C. (2023). Defining intercultural competence: How four pre-service teachers developed a more complex understanding of ICC. Journal of Global Education and Research, 7(1), 1-17.

https://www.doi.org/10.5038/2577-509X.7.1.1210

Corresponding Author

Elizabeth C. Barrow, Georgia Southern University, P.O. Box 8134, Statesboro, GA 30461

Revisions

Submission date: Nov. 13, 2020; 1st Revision: Mar. 3, 2021; 2nd Revision: May 14, 2021; 3rd Revision: Nov. 11, 2021; Acceptance: Nov. 20, 2021 


\title{
Defining Intercultural Competence: How Four Pre-Service Teachers Developed a More Complex Understanding of ICC
}

\author{
Elizabeth Barrow \\ The Department of Middle Grades and Secondary Education \\ Georgia Southern University, United States \\ ebarrow@georgiasouthern.edu
}

\begin{abstract}
This manuscript is one part of a larger exploratory collective case study of pre-service teachers who participated in a student teaching abroad program for one-month in Germany. The objective was to ascertain if and how pre-service teachers with no prior training in intercultural competence (ICC) developed both their understanding and conceptualization of ICC. Data was collected before, during, and after the experience via focus groups, individual interviews, journal entries, and program evaluations. Data was analyzed using a priori codes compiled from Bennett's (2008) characteristics of affective, cognitive, and behavioral competencies of ICC. Findings from this study indicated that a short-term student teaching abroad program has the potential to influence teacher candidates understanding and conceptualization of the complexity of ICC if the program includes an opportunity and space to foster and support critical reflection. Additionally, this study provides one example of how study abroad programs can shift away from quantitative surveys to assess impact and, instead, focus on learner centered evidence collected in real time (Deardorff, 2015).
\end{abstract}

Keywords: international education, teacher education, study abroad, culture shock, collective case study, short-term student teaching abroad

\section{Introduction}

Most pre-service teachers' (PSTs) demographic characteristics, including racial, ethnic, cultural, and linguistic ones, do not mirror those of students in public school classrooms (Ladson-Billings, 2011), especially considering the dramatic change of the ethnic makeup of students in the United States in the last 50 years and continuing today (Banks \& Nguyen, 2008; Krogstad, 2016). Given the challenge of populating classrooms with teachers who reflect their students demographically, another solution must be to create a learning environment that enables all types of students to succeed. One realistic and effective solution is to expand teacher preparation programs to include training that specifically addresses the ICC of PSTs. Such training could foster well-rounded classroom leaders who can teach diverse populations of students successfully.

Course content alone - even if centered on multicultural education, social justice, and culturally responsive practices - is not sufficient to instill predominantly White and middle-class teachers with the knowledge, skills, and attitudes necessary to work with a diverse population of students (Sleeter \& Owuor, 2011). Nor does student teaching in a diverse field placement automatically 
produce a culturally responsive teacher (Sleeter \& Owuor, 2011). Diverse field placements may offer cultural awareness; however, these placements may also inadvertently reinforce stereotypes. Teacher education programs should provide candidates with the opportunity to develop the skills and dispositions needed to be considered interculturally competent. Student teaching abroad, even short-term experiences, provide PSTs with opportunities to learn these skills in a setting that cannot be replicated during traditional student teaching placements.

This manuscript is one part of a larger exploratory collective case study (Stake, 2000; Yin, 2018) of PSTs who participated in a student teaching abroad program for one month in Germany in April 2016. The objective of this portion of the research project was to ascertain if and how PSTs with no prior training in ICC developed both their understanding and conceptualization of ICC. The research question that guided this study was: How does a short-term student teaching abroad experience inform PSTs' understanding of intercultural competence?

\section{Literature Review and Conceptual Framework}

ICC is the knowledge, skills, and behaviors needed to successfully interact in an intercultural setting (Alred et al., 2006; Bennett, 2008; Deardorff, 2006; Fantini, 2009; Spitzberg \& Changnon, 2009). There is no consensus among intercultural scholars about the exact definition of ICC, but three categories of ICC characteristics (skills, knowledge, and attitudes) are largely agreed upon. The characteristics and dimensions of ICC as outlined by Deardorff (2006), and Bennett (2008) were used to analyze the experiences of PSTs in understanding and grappling with their own movement towards ICC.

Table 1. Comparison of ICC Characteristics

\begin{tabular}{ll}
\hline From Deardorff's (2006) Process Model (p. 256) & From Bennett's (2008) ICC Dimensions (pp. 18-20) \\
\hline Knowledge and Comprehension: & Cognitive Dimensions: \\
Cultural self-awareness & Cultural self-awareness \\
Deep cultural knowledge & Culture-general knowledge \\
Sociolinguistic awareness & Culture-specific knowledge \\
& Cultural adaptation process \\
\hline Skills: & Behavioral Dimensions: \\
To listen, observe, and evaluate & Ability to empathize \\
To analyze, interpret, and relate & Ability to listen and gather appropriate information \\
& Ability to manage relationships \\
& Ability to manage social interactions and anxiety \\
\hline Attitudes: & Affective Dimensions: \\
Respect (valuing other cultures) & Curiosity \\
Openness (withholding judgment) & Initiative \\
Curiosity and discovery (tolerating ambiguity) & Risk-taking \\
& Suspension of Judgment \\
& Cognitive flexibility \\
& Tolerance of ambiguity \\
& Cultural humility \\
& Resourcefulness \\
\hline
\end{tabular}

Note. Bennett (2008) refers to the cognitive dimensions as The Mindset, the behavioral dimension as The Skillset, and the affective dimension as The Heartset. Both Deardorff (2006) and Bennett (2008) are recognizing the knowledge, skills, and dispositions needed to be considered interculturally competent. These models indicate that becoming ICC is a multi-step process that requires individuals to consider and work on the way they view themselves and perceive themselves in relation to others in the world and how they project themselves to others. 
For the purposes of this manuscript, ICC is defined as having the skills and mindset to effectively communicate, interact, and appreciate different cultures. The skills needed to effectively communicate and interact with individuals in an intercultural setting align with the skills component of Deardorff's (2006) process model and Bennett's (2008) behavioral competencies (See Table 1). The mindset to effectively communicate and interact with individuals aligns with Deardorff's (2006) knowledge and comprehension phase and Bennett's (2008) cognitive competencies. Finally, the ability to appreciate other cultures aligns with the model's attitudes component and Bennett's (2008) affective competencies.

Deardorff's (2006) developmental process model of ICC and Bennett's (2008) dimensions of ICC are used to show the influence of knowledge and skills, in combination with one's attitude, in yielding a path towards shifting frames of reference (Spitzberg \& Changnon, 2009). A shifting frame of reference implies a movement toward understanding and conceptualizing intercultural interactions in a different culture. An individual's journey to ICC is unique, and as they experience different intercultural interactions, they may gain different attributes of an interculturally competent person. However, it is also possible that individual's experiences can cause them to lose ICC characteristics.

Research on student teaching abroad has demonstrated that participants in international experiences benefit both personally and professionally from their intercultural sojourns (Anderson et al., 2006; Cushner \& Mahon, 2002; Marx \& Moss, 2011; Ozek, 2009; Willard-Holt, 2001; Zhao et al., 2009). Through these experiences, participants gain the knowledge, skills, and attitudes necessary to be considered interculturally competent. Cushner (2008) found that teachers who successfully interact with individuals from a different culture promote ICC for their students as well, while Merryfield (1997) suggested that intercultural experiences have the power to influence pedagogical practices in everyday teaching.

Many scholars have attempted to quantify ICC using the following Likert-scale inventories: global competency and awareness scales (Braskamp et al., 2014; Cushner \& Mahon, 2002; Olsen \& Kroeger, 2001), intercultural sensitivity scales (Hammer et al., 2003; Chen \& Starosta, 2000), culturally responsive teaching and self-efficacy scales (Siwatu, 2007), multicultural teaching competency scales (Prieto, 2012; Spanierman et al., 2011), and the intercultural development inventory (IDI) from Hammer et al. (2003). However, Deardorff $(2006,2015)$ posit that these inventories, which ask questions about fixed points in time, are not a means of evaluating ICC development over time.

The IDI consists of 50 Likert-scale questions designed to measure a person's ICC along the developmental model of intercultural sensitivity (DMIS). The DMIS is used to place a person's worldviews along a scale ranging from ethnocentric orientations (denial, defense, minimization) to ethno-relative orientations (acceptance, adaptations, integration; Bennett \& Bennett, 2004; Hammer et al., 2003). The IDI has been used by a wide range of researchers to explore program duration and program development (Medina-López-Portillo, 2004), to assess the extent to which a short-term study abroad program can influence participant cross-cultural sensitivity (Anderson et al., 2006), to compare STEM and non-STEM participants (Lucietto \& Russell, 2020), to evaluate the degree to which pre-departure orientation sessions influence participant DMIS (Campbell \& Walta, 2015), and to discern whether international curriculum centered around reflection changed a person's ability to work with diverse students (Roller, 2015). These studies all indicate that given 
the opportunity and space to reflect, a person can show growth in intercultural sensitivity and develop a better understanding of ICC. However, these inventories have been designed to evaluate ICC before and after an international experience. This study collected data during an international experience.

Previous research on teacher and teacher candidate ICC understanding has revealed that many educators either do not have the attitudes to support ICC or they are not receiving adequate preparation in their teacher education program (Cushner \& Mahon, 2009). Pederson (1997) revealed that K-12 students were more interculturally sensitive than their teachers and teacher candidates (as cited in Cushner \& Mahon, 2009). Yet it is difficult for teacher education programs to focus on ICC development given accreditation demands and state regulated teacher education curricula (Cushner \& Mahon, 2009). One way to introduce teacher candidates to IDI is through experiential learning or field placements outside of their own culture (Cushner, 2007; Cushner \& Mahon, 2009; Merryfield, 2000).

There are few studies that specifically explore teacher candidate understanding of ICC. Two studies (Akpinar \& Unaldi, 2014; Leutwyler \& Meierhans, 2016) offer opposing views on PSTs' understanding and development of ICC. Akpinar and Unaldi (2014) used a mixed method approach to study the impact of an "academic study visit" (p. 1158) on the ICC development of two groups of participants representing different disciplines. Leutwyler and Meierhans (2016) used quantitative methods to statistically compare how participation in an international student exchange program led to developments of "teaching-specific competencies" (p. 120) such as selfefficacy, flexibility, and motivation to teach compared to students who stayed at the home university. Akpinar and Unaldi (2014) concluded that science teachers showed more growth in ICC (including knowledge, skills, attitudes, and awareness) than the foreign language teachers although both sets showed significant gains in self-awareness.

Conversely, Leutwyler and Meierhans (2016) concluded that intercultural competencies related to teaching, such as self-efficacy and motivation, are not significantly developed during an overseas teaching experience compared to remaining at a home institution. Leutwyler and Meierhans (2016) claimed that previous studies on the impact of student teaching abroad on student teacher selfdevelopment have been overly glorified and have not been methodologically sound since previous studies largely relied on self-reported data.

Leutwyler and Meierhans (2016) have called for researchers to reexamine how they study the impact of student teaching abroad experiences on teacher candidates. The main limitations of previous studies are their reliance on participant self-reported data and retrospective data, many times in the form of a questionnaire sent out months or years after participants return from their international experience, thus leading to "hindsight bias" (Leutwyler \& Meierhans, 2016, p. 129). Very few studies on the impact of student teaching abroad, and specifically studies related to the development of ICC, collect data before, during, and after international sojourns. Previous studies that have relied on self-reported data have not considered that participants may not possess the intercultural maturity to know what they have learned or to know what they do not know (Leutwyler \& Meierhan, 2016). The study reported in this manuscript contributes to the larger body of literature by collecting qualitative data before, during, and after an international study abroad program to ascertain how a short-term student teaching abroad program can contribute to participant understanding of ICC. 


\section{Methods}

This study, a collective case study (Merriam, 1998; Stake, 2000), chronicled PSTs' experiences student teaching abroad individually as one case and then analyzed across the cases to identify commonalities, differences, and generalizations (Goddard, 2010). The individuals are the cases, and they are bound together by the study abroad program.

In collective case studies, the cases should be similar (Stake, 2006). In this study, each participant was a student from a large public university's School of Education teacher preparation program. Each participated in a university-led student teaching abroad program during the last month of his or her student teaching practicum and each had access to the same pack of pre-departure materials and organized experiences in Germany.

\section{Participants}

Participants in this study were from several programs within the School of Education (Early Childhood, Middle Grades, Master of Arts in Teaching, and a fifth-year licensing program for STEM majors). Each participant was treated as an individual case, but collectively the four cases included in this study provided a more generalizable understanding of PSTs' experiences teaching overseas and their development of ICC (Stake, 2006).

The student teaching abroad program was available to undergraduate seniors and master's candidates in the School of Education completing their full-time student teaching practicum during the Spring 2016 semester. Out of 89 students invited to apply, only 7 committed. There was no interview or selection criteria. Participants who completed all stages of the research project received a \$20 Amazon gift card. All seven PSTs participating in the program agreed to participate in the research. Six self-identified as female, and one as male. The females were undergraduate students, and the male was a graduate student. Due to attrition and incomplete data collection, only four of the seven participants finished all surveys and attended all interviews and were therefore selected for inclusion in this study. Of the four participants, only one had taken any German language classes prior to traveling to Germany. Fluency in German is not a pre-requisite for participating in the program; participants were placed in schools with English immersion classes. As part of the pre-departure sessions, participants received a one-hour session on German customs and culture. All names are pseudonyms to protect the anonymity of participants.

\section{Data Collection}

Data collection included an open-ended pre-departure questionnaire, two group interviews (one before departure and one in Germany), individual re-entry interviews, seminar transcripts, participant journals, program evaluations, and an open-ended reflection survey. The pre-departure questionnaire consisted of eight open-ended questions including demographics, travel experience, interactions with individuals from different cultures, and questions pertaining to transformative learning experiences. Participants were also asked to define ICC. This data, collected before the participants' departures to Germany, was analyzed in combination with data collected during and after the study abroad experience and subsequently used as a baseline to analyze the participants' initial understandings of ICC. 
Two group interviews and one individual re-entry interview were conducted with the participants. These group interviews and individual re-entry interviews were semi-structured in nature, audiorecorded, and transcribed verbatim. Each semi-structured group interview took approximately 60 minutes, and individual re-entry interviews lasted between 35 and 70 minutes. Availability ofand convenience for-participants precipitated the need for group interviews. The first group interview took place during a required pre-departure meeting (3/15/16). The second group interview, in Germany, took place following a whole group visit to a local school (4/21/16). Student teachers were located around the suburbs of Germantown and taught in five different schools. Therefore, the location and timing of the second group interview was largely determined by the availability of the participants. The purpose of the final re-entry interview was to give participants an opportunity to reflect on their experience as a whole and how their understanding of ICC did or did not change over time. The four re-entry interviews (one for each person) took place in a reserved conference room in a university library over a two-week period in June 2016.

In lieu of a fourth round of interviews, participants were sent a reflection and follow-up survey in October 2016 using the electronic platform Qualtrics. An open-ended survey was used for two reasons. The first was to allow participants who did not elaborate in the group interviews or their individual interview an opportunity to answer questions in written form. The second was because participants were busy first-year teachers and scattered geographically, thus making an online questionnaire more convenient. Questions in this survey asked participants to reflect on their experiences in Germany and make connections (or not) to their personal and professional lives.

The final stage of data collection was to collect artifacts participants created during their time in Germany. Artifacts included journal entries, program evaluations, and transcripts from the third seminar in Germany (4/27/16). Journal reflections were an important part of this experiential process for the participants as they navigated living and teaching in a different culture. All participants were required to write a daily journal for the entire month of April 2016. These reflections were important for the participants to unpack what they saw and heard and to "analyze their development of intercultural competence" (Deardorff, 2008, p. 45). As a method of data collection, these journals were used to analyze the conceptualization of the participants' ICC over time.

\section{Data Analysis}

Data analysis was conducted in multiple stages, using inductive thematic analysis coding (Braun \& Clarke, 2006). Participants' data were analyzed individually first as part of a comprehensive within-case analysis (Merriam, 1998). MAXQDA was used to assist with the data analysis. Data were first analyzed using a priori codes compiled from Bennett's (2008) characteristics of affective, cognitive, and behavioral competencies of ICC. Texts (journal entries, evaluations, and interview transcripts) were read multiple times and new codes were added. After completing within-case analysis, all four cases were compared as part of a cross-case analysis (Goddard, 2010). Data were chunked together, and common codes collapsed. Emerging themes were identified in analytical memos, which become clear after duplicate codes were combined (Glaser \& Strauss, 1967). 


\section{Findings}

Six unique topics emerged from the data after analyzing PST development and understanding of ICC characteristics: (a) comparing German and American systems of education; (b) comparing German and American curriculum; (c) comparing treatment of refugees and immigrants in Germany and America; (d) speaking English in Germany; (e) learning about oneself; and (f) recognizing multiple perspectives. Similar topics were grouped together and formed four major themes: cross-cultural comparison, sociolinguistic awareness, self-development, and cultural awareness. This manuscript addresses one of the themes, cross-cultural comparisons, as a method of analyzing participant understanding of ICC.

In the context of this manuscript, cross-cultural comparisons refer to the instances in which participants compared German and American values and behaviors, specifically within the context of education. Three major topics emerged within this theme: (a) comparisons of German and American systems of education, (b) comparisons of German students' knowledge of the United States and American students' knowledge of Germany, and (c) comparisons of the treatment of refugees and immigrants in Germany to that of the United States. Through these specific crosscultural comparisons, the PSTs evolved their understanding of ICC.

\section{Comparing German and American Schools}

The PSTs made initial observations about German schools, as evidenced in their journal entries, but they lacked the contextual or historical knowledge to understand their observations. Out of the many observations made by the American PSTs, the most prominent was classroom management.

Participants experienced a type of culture shock whereby their assumptions about how schools should operate did not align with their experiences in schools in Germany. Integrating into a school environment that did not meet these expectations was initially confusing for the PSTs; however, they soon embraced aspects of the German system they found appealing, such as longer breaks between classes and extended lunches. Other differences in schools, such as classroom management, remained shocking. Specifically, the PSTs stated in their journals that the German teachers did not have control over their students. This value-laden language indicated that participants were struggling with their own perceptions of classroom management versus the information they were gathering regarding the German schools. They viewed the German method as the wrong method. In her journal, Gabi reported a classroom management situation that disturbed her.

\footnotetext{
Natalie and I noticed that this was the first class in which the students truly seemed to be disrespectful toward the teacher. Students talked regularly and not even quietly; they were very disruptive. The teacher became noticeably irritated and called the students down several times, but they did not even really stop talking to listen to this. They also mocked her a little. (Gabi, journal entry, 4/7/16)
}

Gabi and Natalie also observed a class where students made slingshots out of metal compasses and the teacher did not attempt to correct the students (Natalie, journal entry, 4/11/16). Sophia made a similar observation in her first-grade class commenting that, "It seems as though the students have little motivation for actually following the rules. There are no consequences or deeper meaning to follow the rules other than the teacher said so" (journal entry, 4/11/16). Bruce also commented on the lack of student motivation: 
Journal of Global Education and Research, Vol. 7, Iss. 1 [2023], Art. 1, pp. 1- 17

It was apparent that the teacher and students were struggling with classroom culture procedures ... to the point where it was distracting and constantly needing to be addressed.... The teacher had several strategies she was clearly trying to enforce [;] ... however many of the students did not seem to seriously pay attention or ignored these used attempts, as consequences were minimal. (Journal entry, 4/5/16)

As seen in the statements above, participants were making value judgments and assumptions about the culture of the German classroom. What they saw enacted in Germany did not coincide with instructions from their home University on building rapport and classroom management techniques. Participants expected to observe classroom management practices similar to their experiences in U.S. classrooms. Instead, they saw classrooms where students were at times unruly and teachers who did little to correct this behavior. Participants never asked their German classroom teachers about what they were observing, thus indicating poorly developed ICC. An individual with a better developed ICC would have asked questions rather than jump to conclusions.

This inability or unwillingness to reevaluate classroom practices suggests that participants were reaching an impasse at the attitude phase of Deardorff's (2006) process model. Prior to departure, participants indicated that ICC was about being "understanding of different cultures" (predeparture surveys). However, when faced with a school culture different from their own expectations, Natalie, Sophia, Bruce, and Gabi all failed to withhold judgment and respect. Instead, they wrote in their journals and shared with each other that the American way of schooling children was better. Despite claiming to possess ICC characteristics, the participants were not exhibiting externally effective and appropriate communication and behavior in an intercultural setting. Natalie, Sophia, Bruce, and Gabi were observing school children's behavior, but they were not interpreting it and relating to the context of the culture of German schools. However, through conversations with German PSTs and professors, all four participants began to gain the skills necessary to analyze and interpret what they were witnessing in their host-schools which led to a general openness and respect for the way German schools and teachers operated.

\section{Unpacking the Disconnect}

Having the opportunity to reflect on what they were seeing and feeling as foreigners in Germany helped the PSTs process these cross-cultural comparisons and engage in the act of being intercultural. Reflections happened in their journals, but mostly through required weekly seminars. Three seminars occurred in Germany. The first was informal and followed a tour of the university. The second was held on April 13, 2016, wherein American PSTs collaborated with some of the German PSTs who had previously traveled to the United States to discuss and compare teacher training and educational systems broadly. In the final seminar on April 27, 2016, American and German PSTs revisited the themes from Seminar 2 and analyzed what they had learned by looking holistically at their comments and observations. Sophia exclaimed that the seminars and discussions were a vital part of the international experience. She stated that they helped her to "unpack and understand the benefits and challenges of both educational systems" and they helped her to "grow as a teacher and a person" (program evaluation).

After the second seminar (4/13/16), Natalie and Gabi began to see the value in how the Germans ran their educational system and even began to question the American system. However, by the time of the third seminar (4/27/16), participants were starting to make progress towards their development of ICC. The following is an excerpt from the third seminar. Gabi is speaking for her 
group. Due to IRB regulations the voices of the German participants are excluded; however, the exchange centers on how the American PSTs came to understand the German system of education specifically in reference to classroom management.

The way that we represented the main idea or conclusion that we came to was that students in our picture for Germany is a teacher and some students on a tandem bicycle and our picture for the U.S. is a teacher on a bicycle pulling all the strings of the wagon. So it's the idea that while the teacher is kinda like leading or directing the classrooms still in Germany the students have to play an active role. The classroom is more centered around them, they are independent, they are responsible for their own success, and if they do not succeed then [it is up to them]. ... Like [the] cultural norm... coming [here] for the first time we were surprised by how little classroom management there was and I think we decided that it's a little bit less of an issue but just kinda something that's a symptom or something that is caused by the cultural idea of who is, who education [is for].

And then I was saying that at this point, the past two weeks since the last seminar I have not noticed behavior management as an issue, not nearly as much. So, it's just something that you get used to.

I don't think it is a matter of easier, I think it's just teachers in the US get blamed a lot more for student behavior; it's like why didn't you stop them from doing that, whereas [in Germany] it was like why were you doing that student.... it's more democratic here. (Gabi, third seminar, 4/27/16)

Gabi's quote is one example of the American PSTs learning through observations of differences and gathering information from discourse with professors, mentors, and peers thus amending their assumptions regarding schooling (Taylor, 1994). Additionally, the presence of a safe space (the seminars) to discuss and grapple with knowledge gain was crucial for the participants' understandings of ICC.

\section{'The Culture Wars'-Comparison of Students' Knowledge Bases}

The American PSTs also compared the curriculum in Germany, specifically secondary education, to that of the United States. Gabi, Natalie, and Bruce were fascinated with a German class on U.S. culture that was required of all seniors. At Second Stadtteilschule, a secondary school, Bruce frequented the Culture Wars class and participated in conversations about the civil rights movement in the United States (group interview 2, 4/21/16; classroom observation, 4/19/21). Natalie and Gabi observed a Culture Wars class on socialism versus capitalism (Natalie, journal entry, 4/5/16), abortion, drug and alcohol use, and purity rings (Natalie, journal entry, 4/28/16). Generally, the PSTs reported being surprised that topics such as abortion were openly discussed and debated in German schools. Here again, the Americans were making a value judgment about German schools, and by default their own schooling experiences, this time focusing on curriculum. Whereas Bruce, Natalie, and Gabi may have developed the characteristics of ICC regarding classroom management, they still struggled to keep an open mind regarding course content.

Lack of knowledge about the world can compound culture shock for individuals traveling overseas and lead to a larger socio-cultural adjustment period. Savicki et al. (2008) referred to this as a "skill deficit" (p. 155) which is illuminated through encounters with the host culture and that some individuals may be unaware of their existence until "something goes wrong" (p. 155). For the Americans in this study, they were unnerved by the open discussion of topics that are considered taboo in Southeastern U.S. schools. Additionally, after multiple interactions with both the Culture Wars classes at their schools and interactions with other German students, all four American PSTs were amazed by how much the average German knew about the United States and how little they 
each knew about Germany. This speaks to the difference in curriculum within the German and American school systems.

While participants may have struggled with keeping an open mind about some classroom content, they were concurrently developing cross-cultural awareness by understanding that others do not have the same worldview as themselves, and that others' perceptions of the United States may not coincide with the participants' own thoughts and assumptions about their own country. The following statement from Gabi is one example of the types of questions the PSTs were asked that contributed to their awareness that not everyone felt the same way about the United States as they did:

One of them asked me if I thought, like did I consider the U.S. to be a terrorist organization. ... During class. And then also children told us that because we have wooden telephone poles, because we have trailer parks, because homework counts as part of your grade and all of those are reasons why the U.S. education system is worse. (Gabi, group interview 2, 4/21/16)

These students had a singular narrative of the United States, just as the PSTs thought that the Germans would be very "cold and not receptive" (Bruce, group interview 2, 4/21/16) and that the students would be very orderly, like in the Sound of Music (group interview 2, 4/21/16). However, their lived realities in Germany did not meet these preconceived ideas, which prompted the participants to start challenging their own assumptions. By challenging assumptions, individuals begin to exhibit Bennett's (2008) affective characteristics of ICC and in turn move toward "effective and appropriate communication and behavior" (Deardorff, 2008, p. 256). Having some of the characteristics of ICC does not make one an interculturally competent person. In other words, an individual may understand and embody affective characteristics, but not behavioral characteristics. To be interculturally competent, one must take the knowledge, skills, and attitudes acquired and use them in such a way that they effectively interact with individuals from the host culture, where effective is defined by members of the host culture. This quote from Gabi exemplifies that transition:

[To] shake assumptions and recognize that we have assumptions and ... instead of just assuming that they are like one way or another and that becomes especially important between cultures because a lot of cultural stuff internalized and implied but I think it can be generalized to interpersonal relations in general because it's hard to know where someone is standing, what their internalized assumptions of the world are. (Group interview 2, 4/21/16)

Participants' cross-cultural comparison of curriculum, specifically in combination with comparisons of German and U.S. schools, broadly served as insight for the Americans into their own assumptions and stereotypes about other countries and to evaluate their own perceptions of the United States. For the participants, a short-term immersion experience was the catalyst needed to gain knowledge about another culture and perceptions of others who are culturally and linguistically dissimilar.

\section{Refugees and Immigrants—Comparing Treatment in Schools}

A final cross-cultural comparison that weighed heavily on the minds of Sophia, Bruce, and Gabi was the treatment of refugees and immigrants in Germany compared to refugees and immigrants in the United States. In April 2016, the number of Syrians seeking asylum in Germany was still a topic of national concern. German Chancellor Angela Merkel's decision to open Germany's 
borders to Syrian refugees was controversial (see Visser \& Roberts, 2016). Participants learned that each state in Germany was responsible for hosting a percentage of the refugees, and that support for Merkel was perceived by some individuals to come from the younger generation (informal conversations, 4/16/16). An influx of non-German speaking individuals, many of whom were of school age, meant an increased stress on schools. Natalie and Gabi mentioned that there was a "refugee class" somewhere in First Gymnasium, an elementary school, but they did not know where, and none of the teachers talked about it (informal conversation, 4/15/16). They could only hypothesize that no one discussed the refugee classes because First Gymnasium was one of the more privileged schools in its district and teachers may have been concerned that recognition of a refugee class would reduce the school's status.

During a planned visit to an urban school with a high immigrant population, Gabi and Sophia had the opportunity to visit a class specifically designed to assist with language instruction (English and German) for new residents. The following quotations illuminate Sophia's and Gabi's different reflections on the refugee situation in Germany and classes designed for German language learners.

I loved my time in their class. It made me realize how much I love diversity and how important it is to encounter people from vastly different walks of life. It opens your eyes and your mind and makes you think critically about your own privilege and experiences. (Sophia, journal entry, 4/21/16)

I observed a class for German language learners. This was a Verbundschule BiSS (Bildung in Sprache und Schrift), or a class for program training in language and writing. On [sic] this class, there were students from Syria, Romania, Turkey, and Russia (and probably other countries I forgot). I liked this class because it was immersive in that the teacher gave instructions in German, but she had a simple and direct style that still helped the students understand what was going on through other means besides language. Through this, I think they were able to connect the language and meaning. (Gabi, journal entry, 4/21/16)

Sophia focused on the students within the class - the students who were learning to speak a new language and the very real emotions she felt while talking with them. Gabi, on the other hand, focused more on the practical elements of the class - the teacher's pedagogy and class structure. In this example, although they took different things away from the class, both Gabi and Sophia were developing behavioral and affective competencies, notably empathy, listening, curiosity, and cultural humility (Bennett, 2008).

Gabi reported developing empathy for individuals who are culturally, religiously, and ethnically different from herself in a way that she did not in her placement in the United States. She did not have extensive training in teaching English Language Learners (ELLs) during her teacher preparation program and did not get to work with ELL students extensively at her U.S. school placement, which partially explains her focus on pedagogy (individual re-entry interview, $6 / 16 / 16)$. She reflected in her journal just days prior to visiting the German language class mentioned above about her own issues learning German and pedagogical techniques used to teach a second language.

At one point while we were in Sport class, I referred to myself as a GLL (German language learner) in kind of an offhand way. This sounded odd, which led me to reflect a bit more on the language-learning aspects of schooling that we have observed. ...I realized that I haven't really seen any students being taught how to speak the dominant or primary language, German. ... I also wonder if GLLs would be treated similarly to how ELLs are treated and if teachers run into similar difficulties when helping these populations. (Gabi, journal entry, 4/17/16) 
After reflecting on her experiences in Germany relating to language - trying to learn German, teaching English to German students, and observing the German language class - she developed a better understanding for the difficulties inherent in teaching students a second language. Gabi used her experiences in Germany to try and understand how second language learners may feel about learning a second or third language and how the experience could be more relevant for students in the United States. She was inspired to teach differently.

Bruce did not comment as frequently on second language acquisition in his journal, but during the second group interview (4/21/16), he reflected on his experiences with language barriers and how difficult it can be to learn in a classroom where you do not speak or understand the native language.

I would just reflect on as personal growth the language, the different perspective of being someone who doesn't speak the native language and being kind of a minority within a German speaking country ... how difficult it really is if you don't, if you come to another country and don't speak the native language how difficult that would be. (Bruce, second group interview, 4/21/16)

Bruce and Gabi's encounters with, and reflections on second language learners may not have inspired them to change the world or live differently, but they were inspired to teach differently and to take the feelings of their ELLs into consideration.

Arguably, PSTs' interaction with recent immigrants to Germany was limited, which is not different from the PSTs' experiences in the United States. Due to timing and the availability of classes, Bruce and Natalie were unable to visit the German language class. Therefore, Bruce's thoughts on the influx of Syrian refugees stemmed from his own observations around Germantown and from conversations with his host parents. Natalie did not mention the refugee situation in any of her interviews, journals, or questionnaires. If she spoke with anyone about this topic, it is not reflected in the data. It is interesting to note what was not talked about in participant journals or the seminars. Although conversations in Germany centered around the influx of Syrian refugees and immigrants to Germany, not one PST made a connection to the influx of immigrants into the United States. They were not even aware of what was going on similarly in their own country and if they had similar experiences back home. Participants made connections to ELL students, and to immigrants, but not to refugees.

In this study, empathy was both a process of developing ICC and an outcome of ICC. According to Daloz (2000, as cited in Bennett, 2008), participants engaged in "constructive engagement with otherness" (p. 19) that resulted in a trigger event that sparked transformative learning (Lyon, 2002). As part of their transformations, Sophia and Bruce processed their interactions with and feelings about immigration and refugees in Germany and the United States, including ideas about the education of immigrants, and came to an understanding of what these individuals might be feeling, even though the participants were not immigrants themselves. Through conversations, observations, and reflection participants empathized with the experiences of another, and as a result, altered their points of view and began to shift their frames of reference (Mezirow, 1997). Yet even though PSTs were developing empathy for immigrants and refugees in Germany, the lack of connection back to similar situations in the United States was concerning. Here participants were demonstrating the heartset and skillset of ICC characteristics, but not the mindset (Bennett, 2008). Bruce, Sophia, and Gabi were curious to learn about the experiences of refugees in Germany, and they developed some level of empathy, but they did not display ICC characteristics 
of cultural self-awareness. Perhaps a longer international experience could have allowed the PSTs the opportunity to develop these specific ICC characteristics.

\section{Conclusions}

Bruce, Natalie, Sophia, and Gabi received no training or instruction specific to ICC prior to this study. Participants' understandings of ICC ebbed and flowed as they experienced new cultural interactions and reflected on their reactions to these experiences. These early experiences highlighted individual skills, knowledge, and attitudes, specifically the characteristic of respect or valuing other cultures and withholding judgment. Bruce, Natalie, Sophia, and Gabi all vocalized the need to have respect for other cultures, yet when faced with cultural norms different from their own (such as classroom management in German schools), all four participants initially failed to act in an interculturally competent way. Despite a disconnect between words and actions, throughout the four-week international exposure, Bruce, Natalie, Sophia, and Gabi all displayed movement in their understandings of ICC.

Initial understandings of ICC by the PSTs were about interacting with individuals from different cultures in a variety of contexts but not necessarily about the skills, attitudes, and behaviors necessary to interact with different individuals effectively. The changes in cross-cultural awareness that PSTs went through afforded them the opportunity to not only articulate what being an ICC individual may look like, but also to enact some of the attitudes and skills necessary to be ICC. Many situations encountered by the PSTs while in Germany could have contributed to a more complex understanding of ICC; however, it was comparing and analyzing cross-cultural experiences specific to schooling that facilitated a deeper understanding on some ICC characteristics. Looking back at Bennett's (2008) dimensions, participants demonstrated many of the behavioral and attitudinal characteristics of ICC, but only minimally within the cognitive dimension. This may be due in part to a lack of structured pre-departure sessions centered on ICC training.

This study confirms findings from other studies (i.e., Nguyen, 2017) that short-term student teaching abroad programs can influence participants' understanding and skills of ICC. Study abroad programs should be intentional when designing international experiences for participants. For instance, pre-departure sessions are pivotal for participant success in an international setting. Although individuals self-select to participate in a study abroad program, they do not intuitively know how to behave in interculturally competent ways. Nguyen (2017) posited that strategic reentry programs can help cement participants' ICC knowledge and skills for longer periods of time.

This study adds to the body of literature on short-term study abroad programs by confirming that being intentional with programming during an international experience helps promote ICC development. In this study, the seminars PSTs attended during their sojourns provided a safe and trustworthy space for participants to grapple with what they were observing in schools and to engage in critical discourse with their peers and German contemporaries. Participants need opportunities to speak about what they are observing, to ask questions, and to converse about their understanding of situations. As participants reflect, they may recognize assumptions or judgments they have made and potentially challenge or change them. Participants need not abandon their own worldviews; rather, they can accept that their worldview is not the only one (Hanvey, 1982). This 
reflective process equips PSTs to understand better the various worldviews that their students bring to the classroom.

A short-term student teaching abroad program has the potential to influence teacher candidates' understanding and conceptualization of the complexity of ICC if the program includes an opportunity for space to have meaningful and safe conversations. Using Deardorff's (2006) process model of ICC, Bennett's (2008) ICC competencies, and data collected from interviews, focus groups, and journal entries, it can be concluded that participant understanding of ICC did evolve over time. Movement by participants was not substantial; however, this study demonstrates that it is possible for a short-term international experience to inform ICC knowledge and development. Participant understanding of ICC morphed after spending one month living and working in Germany, and again after participants returned from their experience. Interestingly participants' actions did not match their original ideas of what it means to be intercultural, but after working through their initial experiences with the help of German PSTs and professors, Bruce, Natalie, Gabi, and Sophia reversed their previous judgments to make room for a more open mindset to different cultures.

\section{Theoretical Implications}

The results of this study confirm Deardorff's (2015) call to change how educators assess the impact of study abroad programs. Specifically, Deardorff (2015) supported a shift from traditional to authentic evidence collection; a shift away from pre- and post-tests and towards evidence collected in the real-world environment. This study collected evidence in real time through classroom observations, in-country interviews and conversations, and participants' daily journals. While surveys like the IDI (Hammer et al., 2003) provide valuable insight into participants' ICC orientations, they are not a representation of an individual's journey. ICC development is not linear and does not occur at a set pace. To truly understand the influence of an international experience, researchers must invest in evaluating the process and not rely solely on numbers (Deardorff, 2015).

\section{Practical Implications}

The results of this study confirm findings from other studies and can be used by study abroad program directors to plan and implement intentional and meaningful opportunities for participants to develop their own understandings of ICC. However, planning intentional and meaningful opportunities does not mean participants are guaranteed to show movement in ICC. Therefore, the following recommendations are presented. First, programs should provide pre-departure sessions that include instruction in the official language of the host country and cultural norms pertaining to communication expectations. Second, programs should include opportunities for participants to immerse themselves in the culture, such as field trips to local sites, living with host families, and working alongside locals (see Snodgrass et al. [2021] for the Live-Learn-Work model). Lastly, programs must allow participants multiple opportunities to reflect and debrief throughout the entire experience. In the moment debriefing with faculty members was crucial for participants in this study. 


\section{Limitations and Future Research}

As with any research project of this size, this study is not without limitations. First, the sample size was small. Given the very small sample size, the results are not conducive to larger generalizability. Second, there was little demographic diversity. All participants were White, and only one identified as male. No socioeconomic data were collected; however, participants were able to afford the cost of student teaching abroad (approximately $\$ 4,000$ ). Finally, participants self-selected to participate in an international teaching experience; thus, they likely already possessed some of the dispositions of an interculturally competent person. Future studies should include a larger sample size with more gender, race, and social class variability by providing scholarships and other incentives to offset the out-of-pocket expenses.

Another limitation is the reliance on some self-reported data. This study began to fill a gap in the research literature by interviewing participants before, during, and after their international experience and by not relying on quantitative inventories to predict or define growth. However, the journals and surveys contained self-reported data. It is possible that participants did not express themselves honestly in these documents because they knew others would read them. The program evaluation sent out by the University was supposed to be confidential, but participants were required to put their name on the form so that the program director knew who completed the evaluations. This identification could have led to misinformation that skewed the data. More research is needed to ascertain the longitudinal effect of the international experience on individual's understanding of ICC.

\section{References}

Akpinar, K. D., \& Unaldi, I. (2014). Exploring intercultural competence in teacher education: A comparative study between science and foreign language teacher trainers. Educational Research and Reviews, 9(21), 11561164.

Alred, G., Byram, M., \& Fleming, M. (2006). Introduction. In G. Alred, M. Byram, \& M. Fleming (Eds.), Education for intercultural citizenship (13th ed., pp. 1-8). Multilingual Matters.

Anderson P. H., Lawton, L., Rexeisen, R. J., \& Hubbard, A. C. (2006). Short-term study abroad and intercultural sensitivity: A pilot study. International Journal of Intercultural Relations, 30(4), 457-469.

Banks, J. A., \& Nguyen, D. (2008). Diversity and citizenship education: Historical, theoretical, and philosophical issues. In L. S. Levstik, \& C. A. Tyson (Eds.), The handbook of research in social studies education (pp. 137-151). Routledge.

Bennett, J. M., \& Bennett, M. J. (2004). Developing intercultural sensitivity: An integrative approach to global and domestic diversity. In D. Landis, J. M. Bennett, \& M. J. Bennett (Eds.), The handbook of intercultural training (3rd ed., pp. 147-165). Sage.

Bennett, J. M. (2008). On becoming a global soul: A path to engagement during study abroad. In V. Savicki (Ed.), Developing intercultural competence and transformation: Theory, research, and application in international education (pp. 13-31). Stylus.

Braskamp, L. A., Braskamp, D. C., \& Engberg, M. E. (2014). Global perspective inventory (GPI): Its purpose, construction, potential uses, and psychometric characteristics. Global Perspectives Institute. https://citeseerx.ist.psu.edu/viewdoc/download?doi=10.1.1.584.9216\&rep=rep1\&type=pdf

Braun, V., \& Clarke, V. (2006). Using thematic analysis in psychology. Qualitative Research in Psychology, 3(2), $77-101$

Campbell, C. J. L., \& Walta, C. (2015). Maximizing intercultural learning in short term international placements: Findings associated with orientation programs, guided reflection, and immersion. Australian Journal of Teacher Education, 40(10), 1-15.

Chen, G., \& Starosta, W. J. (2000). The development and validation of the intercultural sensitivity scale. Human Communication, 3, 1-15. 
Cushner, K., \& Mahon, J. (2002). Overseas student teaching: Affecting personal, professional, and global competencies in an age of globalization. Journal of Studies in International Education, 6(1), 44-58. https://doi.org/10.1177/1028315302006001004

Cushner, K., \& Mahon, J. (2009). Intercultural competence in teacher education: Developing the intercultural competence of educators and their students. In D. Deardorff (Ed.), The SAGE handbook of intercultural competence (pp. 304-320). Sage.

Cushner, K. (2007). The role of experience in the making of internationally-minded teachers. Teacher Education Quarterly, 34(1), 27-39.

Cushner, K. (2008). International socialization of young people: Obstacles and opportunities. International Journal of Intercultural Relations, 32(2), 164-173. https://doi.org/10.1016/j.ijintrel.2007.09.004

Deardorff, D. K. (2006). Identification and assessment of intercultural competence as student outcome of internationalization. Journal of Studies in International Education, 10(3), 241-266. https://doi.org/10.1177/1028315306287002

Deardorff, D. K. (2008). Intercultural competence: A definition, model, and implications for study abroad. In V. Savicki (Ed.), Developing intercultural competence and transformation: Theory, research, and application in international education (pp. 32-52). Stylus.

Deardorff, D. K. (2015). International education outcomes assessment: A changing paradigm. IIE Networker. https://www.nxtbook.com/naylor/IIEB/IIEB0215/index.php\#/p/18

Fantini, A. E. (2009). Assessing intercultural competence: Issues and tools. In D. Deardorff (Ed.), The SAGE handbook of intercultural competence (pp. 456-476). Sage.

Glaser, B. G., \& Strauss, A. L. (1967). The discovery of grounded theory: Strategies for qualitative research. Aldine.

Goddard, J. T. (2012). Collective case studies. In A. J. Mills, G. Durepos, \& E. Wiebe (Eds.), Encyclopedia of case study research (pp. 164-165). Sage.

Hammer, M. R., Bennett, M. J., \& Wiseman, R. (2003). Measuring intercultural sensitivity: The intercultural development inventory. International Journal of Intercultural Relations, 27(4), 421-443. https://doi.org/10.1016/S0147-1767(03)00032-4

Hanvey, R. (1982). An attainable global perspective. Theory Into Practice, 21(3), 162-167.

Krogstad, J. M. (2016, February 3). 2016 electorate will be the most diverse in U.S. history. Pew Research Center. http://www.pewresearch.org/fact-tank/2016/02/03/2016-electorate-will-be-the-most-diverse-in-u-s-history/

Ladson-Billings, G. (2011). Is meeting the diverse needs of all students possible? Kappa Delta Phi Record, 48(1), 13-15. https://doi.org/10.1080/00228958.2011.10516716

Leutwyler, B., \& Meierhans, C. (2016). Effects of international student exchange on pre-service teachers: A quasiexperimental study. Intercultural Education, 27(2), 117-136. https://doi.org/10.1080/14675986.2016.1144713

Lucietto, A. M., \& Russell, L. (2020). Comparison of pre-intervention IDI results from STEM and non-STEM undergraduate students. Journal of Global Education and Research, 4(2), 113-124. https://www.doi.org/10.5038/2577-509X.4.2.1051

Lyon, C. R. (2002, May 24-26). Trigger event meets culture shock: linking the literature of transformative learning theory and cross-cultural adaptations [Conference presentation]. Annual Meeting of the Adult Education Research, Raleigh, NC, United States.

Marx, H., \& Moss, D. M. (2011). Please mind the culture gap: Intercultural development during a teacher education study abroad program. Journal of Teacher Education, 62(1), 35-47. https://doi.org/10.1177/0022487110381998

Medina-López-Portillo, A. (2004). Intercultural learning assessment: The link between program duration and the development of intercultural sensitivity. Frontiers: The Interdisciplinary Journal of Study Abroad, 10(1), 179-199.

Merriam, S. B. (1998). Qualitative research and case study applications in education. Jossey-Bass.

Merryfield, M. M. (1997). A framework for teacher education in global perspectives. In M. M. Merryfield, E. Jarchow, \& S. Pickert (Eds.), Preparing teachers to teach global perspectives (pp. 1-24). Corwin.

Merryfield, M. M. (2000). Why aren't teachers being prepared to teach for diversity, equity, and global interconnectedness? A study of lived experiences in the making of multicultural and global educators. Teacher and Teacher Education, 16(4), 429-443. https://doi.org/10.1016/S0742-051X(00)00004-4

Mezirow, J. (1997). Transformative learning: Theory to practice. New Directions for Adult and Continuing Education, Summer 74, 5-12. https://doi.org/10.1002/ace.7401 
Nguyen, A. (2017). Intercultural competence in short-term study abroad. Frontiers: The Interdisciplinary Journal of Study Abroad, 29(2), 109-127.

Olsen, C. L., \& Kroeger, K. R. (2001). Global competency and intercultural sensitivity. Journal of Studies in International Education, 5(2), 116-137. https://doi.org/10.1177/102831530152003

Ozek, Y. (2009). Overseas teaching experience: Student teachers' perspectives of teaching practicum. Procedia Social and Behavioral Sciences, 1(1), 2541-2545. https://doi.org/10.1016/j.sbspro.2009.01.448

Prieto, L. R. (2012). Initial factor analysis and cross-validation of the multicultural teaching competencies inventory. Journal of Diversity in Higher Education, 5(1), 50-62. http://dx.doi.org/10.1037/a0026199

Roller, K. M. (2015). Pre-service teachers and study abroad: A reflective, experiential sojourn to increase intercultural competence and translate the experience into culturally relevant pedagogy. In P. C. Layne, \& P. Lake (Eds.), Global innovation of teaching and learning in higher education (pp. 107-128). Springer.

Savicki, V., Adams, I., \& Binder, F. (2008). Intercultural development: Topics and sequences. In V. Savicki (Ed.), Developing intercultural competence and transformation: Theory, research, and application in international education (pp. 154-172). Stylus.

Siwatu, K. O. (2007). Pre-service teachers' culturally responsive teaching self-efficacy and outcome expectancy beliefs. Teaching and Teacher Education, 23(7), 1086-1101. https://doi.org/10.1016/j.tate.2006.07.011

Sleeter, C. E., \& Owuor, J. (2011). Research on the impact of teacher preparation to teach diverse students: The research we have and the research we need. Action in Teacher Education, 33(5-6), 524-536. https://doi.org/10.1080/01626620.2011.627045

Snodgrass, L. L., Hass, M., \& Ghahremani, M. (2021). Developing cultural intelligence: Experiential interactions in an international internship program. Journal of Global Education and Research, 5(2), 165-174. https://www.doi.org/10.5038/2577-509X.5.2.1078

Spanierman, L. B., Oh, E., Heppner, P. P., Neville, H. A., Mobley, M., Wright, C. V., Dillon, F. R., \& Navarro, R. (2011). The multicultural teaching competency scale: Development and initial validation. Urban Education, 46(3), 440-464. https://doi.org/10.1177/0042085910377442

Spitzberg, B. H., \& Changnon, G. (2009). Conceptualizing intercultural competence. In D. Deardorff (Ed.), The SAGE handbook of intercultural competence (pp. 2-52). Sage.

Stake, R. E. (2000). Case studies. In N. K. Denzin, \& Y. S. Lincoln (Eds.). Handbook of qualitative research (2nd ed., pp. 134-164). Sage.

Stake, R. E. (2006). Multiple case study analysis. Guilford.

Taylor, E. W. (1994). A learning model for becoming interculturally competent. International Journal of Intercultural Relations 18(3), 389-408. https://doi.org/10.1016/0147-1767(94)90039-6

Visser, S., \& Roberts, E. (2016, September 5). Angela Merkel admits immigration policy hurt party in elections. CNN. http://www.cnn.com/2016/09/04/europe/germany-alternative-fur-deutschland-afd-angela-merkel/

Willard-Holt, C. (2001). The impact of short-term international experience for pre-service teachers. Teaching and Teacher Education, 17(4), 505-517. https://doi.org/10.1016/S0742-051X(01)00009-9

Yin, R. K. (2018). Case study research: Design and methods (6th ed). Sage.

Zhao, Y., Meyers, L., \& Meyers, B. (2009). Cross-cultural immersion in China: Preparing preservice elementary teachers to work with diverse student populations in the United States. Asia-Pacific Journal of Teacher Education, 37(3), 295-317. 